\title{
Chest, Abdomen or Back: Selecting an Optimum Trunk Region for Hardy and DuBois' Weighted Mean Skin Temperature Formula
}

\author{
Joo-Young LeE, Kouhei NAKaO and Yutaka TochiHARA \\ Department of Human Science, Kyushu University, Japan \\ E-mail: leex3140@design.kyushu-u.ac.jp
}

(received on August 13, 2010, accepted on November 19, 2010)

\begin{abstract}
The purpose of the present study was to examine the extent of the variations in mean skin temperatures by Hardy and DuBois' 7-point formula when different single trunk sites were assigned $\left(\overline{\bar{T}}_{\text {sk-chest }}, \overline{\mathrm{T}}_{\text {sk- }}\right.$ abdomen, and $\overline{\mathrm{T}}_{\text {sk-upper back }}$ for the chest, abdomen and back, respectively). The average of the three trunk sites $\left(\overline{\mathrm{T}}_{\text {sk-all }}\right)$ was considered as a reference value. Eight male subjects underwent twelve experimental conditions: activities (rest and exercise) $\times$ clothing (Control, Tyvek and Vinyl condition) $\times$ air temperatures $(25$ ${ }^{\circ} \mathrm{C}$ and $32^{\circ} \mathrm{C}$ ). The results showed that 1 ) for rest conditions, there was no difference among $\overline{\mathrm{T}}_{\text {sk-chest }}, \overline{\mathrm{T}}_{\text {sk- }}$ abdomen, $\overline{\mathrm{T}}_{\text {sk-upper back }}$, and $\overline{\mathrm{T}}_{\text {sk-all }} ; 2$ ) for exercising conditions at $25^{\circ} \mathrm{C}, \overline{\mathrm{T}}_{\text {sk-upper back }}$ tended to be greater than $\overline{\mathrm{T}}_{\text {sk-chest }}$, and $\overline{\mathrm{T}}_{\text {sk-abdomen. }}$. The differences were statistically significant for Control and Tyvek conditions $(p<0.05) ; 3)$ for Control during exercise, $\bar{T}_{\text {sk-abdomen }}$ was significantly lower than $\left.\bar{T}_{\text {sk-upper back }}(p<0.05) ; 4\right)$ $\overline{\mathrm{T}}_{\text {sk-all }}$ were not statistically distinguished from $\overline{\mathrm{T}}_{\text {sk-chest }}, \overline{\mathrm{T}}_{\text {sk-abdomen }}$, and $\left.\overline{\mathrm{T}}_{\text {sk-upper back }} ; 5\right)$ for Control during exercise, $\overline{\mathrm{T}}_{\text {sk-upper back }}$ overestimated $\overline{\mathrm{T}}_{\text {sk-chest }}$ and $\overline{\mathrm{T}}_{\text {sk-abdomen }}$ at $\mathrm{T}_{\mathrm{a}} 25^{\circ} \mathrm{C}$, while $\overline{\mathrm{T}}_{\text {sk-abdomen }}$ underestimated $\overline{\mathrm{T}}_{\text {sk-upper back }}$ at $T_{a} 32^{\circ} \mathrm{C}$. The variations were attributable to the differences in thermal dynamics of the abdomen and upper back tissues during exercise. For estimating the $\overline{\mathrm{T}}_{\mathrm{sk}}$ of lightly clothed male subjects during exercise using Hardy and DuBois' 7-point formula, reliance on the abdomen or the upper back as a site representative of the trunk is not recommended, but the average of the chest, abdomen, and back temperatures is recommended as the trunk temperature. In the case that the minimum number of skin sites is required due to dynamic exercise, a preferred single site on the trunk was the chest for male subjects.
\end{abstract}

Keywords: Weighted mean skin temperature, Trunk temperature, Hardy and DuBois' equation, Exercise, Clothing

\section{Introduction}

The initial interest in mean skin temperature $\left(\overline{\mathrm{T}}_{\mathrm{sk}}\right)$ originated from discussions concerning the estimation of mean body temperature (Burton, 1935; Hardy \& DuBois, 1938). The change in mean body temperature reflects body heat storage, which is a necessary term to quantify heat exchange between the human body and the surrounding environment. The crucial role of calculating mean skin temperature in the evaluation of body heat exchange as well as in the evaluation of thermal comfort, has resulted in a number of attempts to derive equations being made, in order to estimate mean skin temperatures with various logics (e.g., simple average, one point, skin surface area ratio, skin surface area ratio and sensitivity of the skin, skin surface area ratio and heat transfer coefficient ratio, etc.). Among the various methods employed, mean skin temperature that is based on the skin surface area ratio to the total body surface area has been the most widely accepted. This is because this method more faithfully represents the definition of 'mean skin temperature'.

Among these formulas, Hardy and DuBois' 7point formula has been the most commonly used, due to its balanced choice of body segments and reliable weighted coefficients, along with its historical contribution: $\quad \overline{\mathrm{T}}_{\text {sk }}=0.07 \mathrm{~T}_{\text {head }}+0.35 \mathrm{~T}_{\text {trunk }}+0.14 \mathrm{~T}_{\text {arms }}+0.05$ $\mathrm{T}_{\text {hands }}+0.19 \mathrm{~T}_{\text {thighs }}+0.13 \mathrm{~T}_{\text {legs }}+0.07 \mathrm{~T}_{\text {feet }}$ (Hardy \& DuBois, 1938). Significantly however, the original draft of Hardy and DuBois' 7-point formula (Hardy \& DuBois, 1938) did not stipulate any specified trunk parts. They measured a total of 20 skin temperatures including the following four trunk parts: the chest, abdomen, upper back, and lower back. Thereafter, they used the average of the four trunk temperatures as the single trunk temperature $\left(\mathrm{T}_{\text {trunk }}\right)$ of the formula. Perhaps inevitably therefore, the trunk site in the Hardy and DuBois' formula has since been cited 
without a consensus as to the exact location that should be used to take measurements on the trunk. A group of studies have used the abdomen as the trunk region in Hardy and DuBois' 7-point formula in their reviewed tables (Houdas \& Ring, 1982; Kuwabara et al., 2006; Mitchell \& Wyndham, 1969; Nielsen \& Nielsen, 1984; Parsons, 2003), while another group of studies marked the chest (Choi et al., 1997; Lund \& Gisolfi, 1974; Teichner, 1958).

The site selection on the trunk would not be problematic if skin temperatures over the entire trunk are relatively uniform or if the regional portion taken by the trunk in the total body surface area is negligible. However, the regional surface area of the trunk part amounts to $35.9 \%$ for Asian adult males (Lee \& Choi, 2009). In the majority of formulas, the torso is assigned with a greater weighting factor than other body surface areas, ranging from 0.5 (Burton, 1935) to 0.35 (Hardy \& DuBois, 1938). Because of the great percentage of the trunk part, whether the chest, abdomen, or back is chosen may have a significant influence on the determination of mean skin temperature. A number of studies reported that the temperature distribution over the trunk is not homogeneous. Frim et al. (1990) found that temperature differences among immediate skin temperatures at a radius of $5 \mathrm{~cm}$ surrounding the target point on trunk sites amounted to approximately $1^{\circ} \mathrm{C}$ at an air temperature $\left(\mathrm{T}_{\mathrm{a}}\right)$ of $28^{\circ} \mathrm{C}$ and $2-3^{\circ} \mathrm{C}$ at an $\mathrm{T}_{\mathrm{a}}$ of $18^{\circ} \mathrm{C}$. They concluded that errors in mean skin temperature measurement could arise from the differences in the probe location. The front torso sites (the chest and abdomen) normally used for the determination of mean skin temperature were cooler than the surrounding regions on the frontal trunk when examined throughout infrared (IR) thermography (Livingstone et al., 1988). A temperature value measured by a single thermistor can differ by as much as $3^{\circ} \mathrm{C}$ from the mean temperature corresponding area determined by IR thermography (Livingstone et al., 1987). In a thermal neutral environment, the total range from maximum to minimum in the variations of temperatures within one body region exceeds by $3{ }^{\circ} \mathrm{C}$ (Kaufman \& Pittman, 1966). In this regard, IR thermometry might have the ground-breaking potential to fulfill the calculation of true mean skin temperature, because the IR thermometry does not require assumptions that the specified body site on a body segment represents the average surface temperature of that segment of the body, and the ratios of regional body surface area are on average identical in people with different body shapes. However, IR thermometry is of no use for the measurement of skin temperatures beneath clothing. The conventional contact thermometry is still necessary to determine mean skin temperature for clothed persons.
The greater the number of skin temperature measurements, the greater the accuracy of the estimation. However, the fewer the sites used the better, especially during dynamic activities to avoid complex and inhibitive wiring. Therefore, the purpose of the present study was to examine the extent of the variations in mean skin temperatures at various environmental combinations when different trunk sites (the chest, abdomen and back) were chosen as the representative site for the trunk, and to suggest the most valid site for representation in Hardy and DuBois' 7point formula.

\section{Methods}

\section{Physical characteristics of subjects}

Eight healthy male university students [Mean \pm

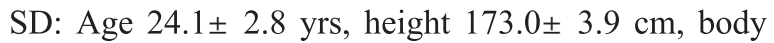
mass $66.3 \pm 9.7 \mathrm{~kg}$, body surface area $1.82 \pm 0.13 \mathrm{~m}^{2}$, body fat $(\% \mathrm{BF}) 17.3 \pm 4.7 \%$, peak oxygen uptake $\left(\dot{V} \mathrm{O}_{2 \text { peak }}\right) 48.0 \pm 16.7 \mathrm{ml} \mathrm{kg}^{-1} \mathrm{~min}^{-1}$, maximum heart rate $\left(\mathrm{HR}_{\max }\right) 193 \pm 8 \mathrm{bpm}$ ] participated in this study. For the determination of $\dot{V} \mathrm{O}_{2 \text { peak }}$, subjects performed a graded exercise test using a treadmill in a climatic chamber at an air temperature $\left(T_{\mathrm{a}}\right)$ of $25^{\circ} \mathrm{C}$ with $50 \%$ relative humidity $(\mathrm{RH})$ according to the Bruce Treadmill protocol. Their expired gas was continuously measured by an automatic respiromonitor (AE300S, Minato Medical Science, Japan). During the $\dot{V} \mathrm{O}_{2 \text { peak }}$ test, heart rate was simultaneously monitored every second (RS400, Polar Electro Oy, Finland). Body surface area was estimated according to Lee et al. (2008). The total body fat $(\% \mathrm{BF})$ was estimated using a bioelectrical impedance method (Karada Scan HBF-354, OMRON Co. Ltd, Japan). Skinfold thickness was determined using a caliper (Eiken, Japan) on the chest, abdomen and upper back of the subject standing and relaxed. Three readings were taken at each site with the same investigator, and the mean of the three readings was used (mean \pm SD: $12.1 \pm 6.9$ $\mathrm{mm}$ on the chest, $15.9 \pm 7.9 \mathrm{~mm}$ on the abdomen, and $14.5 \pm 3.3 \mathrm{~mm}$ on the upper back. There was no significant difference among three parts). None of the subjects were professional athletes. All tests were performed in the middle of summer (July to Sep 2009). Before participation, subjects completed a health status questionnaire and signed a written informed consent form. The experimental protocol was approved by the Institutional Review Board of the Kyushu University.

\section{Experimental conditions: climate, clothing and activity}

Experimental conditions consisted of a total of 12 conditions: two activities $\times$ three clothing levels $\times$ two air temperatures $\left(\mathrm{T}_{\mathrm{a}}\right.$ of $25^{\circ} \mathrm{C}$ and $32^{\circ} \mathrm{C}$ with $50 \%$ $\mathrm{RH}$ in still air). Three types of experimental ensembles 
were employed: Control (Total clothing weight of $590 \mathrm{~g}$ except running shoes), Tyvek condition (787g), and Vinyl condition $(1,245 \mathrm{~g})$. For Control, subjects wore a round T-shirt with short sleeves, under shorts, shorts, a mesh vest, socks and running shoes. For Tyvek condition, subjects added the following items to the Control: Dupont Tyvek coverall (140g in total mass, Polypropylene $100 \%, 0.50 \mathrm{~mm}$ in thick, air permeability of $118 \mathrm{~cm}^{3} \square \mathrm{cm}^{-2} \square \mathrm{sec}^{-1}$ ), cotton gloves and Tyvek shoe-covers. For Vinyl condition, vinyl coverall, rubber gloves, vinyl shoes covers, and vinyl boots covers were added to Tyvek condition, removing Tyvek shoe covers. The entire surface of the vinyl coverall was made of vapor impermeable material, generally known as transparent PVC. Both Tyvek and Vinyl coveralls had their hoods and elastic cuffs around the wrists and ankles attached. Only the forehead and eyes were exposed for Tyvek and Vinyl conditions. Clothing insulation $\left(\mathrm{I}_{\mathrm{cl}}\right)$ and evaporative heat resistance were directly determined using a sweating thermal manikin with 17 body segments (JUN, KEM, Japan; BSA $1.658 \mathrm{~m}^{2}$ ) in a standing posture. The $\mathrm{I}_{\mathrm{cl}}$ were $0.37,0.71$ and 0.78 clo for Control, Tyvek, and Vinyl conditions, respectively.

Two levels of metabolic activities were assigned at (1) rest on a chair and (2) exercise on the treadmill. Participants underwent both rest (60 minutes per trial) and exercise conditions ( 80 minutes per trial) on different days. For the exercise protocol, they performed two bouts of exercise on the treadmill at a speed of 6-8 $\mathrm{km} \square \mathrm{hr}^{-1}\left(318 \pm 48 \mathrm{~W} \square \mathrm{m}^{-2}\right.$ for Control at the $\mathrm{T}_{\mathrm{a}}$ of 25 ${ }^{\circ} \mathrm{C}$, mean \pm SD of eight subjects). The exercise protocol consisted of 10 min-stabilization on a chair, 20 min-exercise on a treadmill, 10 min-rest on the chair, 20 min-exercise on the treadmill, and 20 min-recovery on the chair. Only for the Vinyl condition at the $\mathrm{T}_{\mathrm{a}}$ of $32^{\circ} \mathrm{C}$, was the test protocol shortened to $10 \mathrm{~min}$ stabilization, $20 \mathrm{~min}$-exercise and $10 \mathrm{~min}$-rest without repetition (40 minutes per trial). The exercise sessions were performed with a minimum of two day intervals between each session. The trial order was counterbalanced across subjects.

\section{Measurements and calculations of skin temperatures $\left(T_{s k}\right)$}

Skin temperature $\left(\mathrm{T}_{\mathrm{sk}}\right)$ was recorded every two seconds on the forehead (mid-point), chest $(3 \mathrm{~cm}$ above the nipple), abdomen $(3 \mathrm{~cm}$ apart from the navel), upper back (scapular), upper arm (lateral), forearm (frontal, hairless), hand (dorsal), thigh (frontal mid-point), calf (lateral), and foot (dorsal) (LT-8A, Gram Ltd, Japan). All temperature sensors were attached on the left side, except the forehead. Mean skin temperature $\left(\overline{\mathrm{T}}_{\mathrm{sk}}\right)$ was determined from the following Hardy and DuBois' 7-point formula: $\overline{\mathrm{T}}_{\mathrm{sk}}=0.07 \mathrm{~T}_{\text {head }}+$
$0.35 \mathrm{~T}_{\text {trunk }}+0.14 \mathrm{~T}_{\text {arms }}+0.05 \mathrm{~T}_{\text {hands }}+0.19 \mathrm{~T}_{\text {thighs }}+0.13$ $\mathrm{T}_{\text {legs }}+0.07 \mathrm{~T}_{\text {feet }}$. In the present study, $\overline{\mathrm{T}}_{\text {sk-chest }}, \overline{\mathrm{T}}_{\text {sk-abdomen}}$, and $\overline{\mathrm{T}}_{\text {sk-upper back }}$ stand for mean skin temperature that was derived using chest, abdomen, and upper back temperature, respectively, as the $\mathrm{T}_{\text {trunk }}$ in Hardy and DuBois' 7-point formula. $\overline{\mathrm{T}}_{\text {sk-all }}$ stands for mean skin temperature that was derived using the average of chest, abdomen, and upper back temperatures as the $\mathrm{T}_{\text {trunk }} . \overline{\mathrm{T}}_{\text {sk-all }}$ was considered as a reference value in the present study. Apart from Hardy and DuBois' 7-point formula, $\overline{\mathrm{T}}_{\mathrm{sk}}$ by Ramanathan's 4-point formula (Ramanathan, 1964) was calculated $\left(\overline{\mathrm{T}}_{\mathrm{sk}-4 \mathrm{pts}}\right)$ because Ramanathan's 4-point formula is commonly recommended in warm environments and/or exercising conditions (Berger \& Grivel, 1989; Mairiaux et al., 1987; Mitchell \& Wyndham, 1969).

\section{Procedures}

Subjects rested approximately 60 minutes in a preparation room that was maintained at a $\mathrm{T}_{\mathrm{a}}$ of $22-24$ ${ }^{\circ} \mathrm{C}$ during instrumentation. After voiding, subjects were permitted to drink freely before the commencement of testing to achieve eu-hydrated state. Wearing only under shorts they were then weighed on a body scale. After body weight measurement, the instrumentation of temperature sensors was completed on the subjects before experimental clothing was donned in the pre-test room. After confirming rectal temperature within normal ranges $\left(37.0 \pm 0.4^{\circ} \mathrm{C}\right)$, subjects entered the experimental chamber that was maintained at the target environmental condition of the session. During the test, subjects were prohibited to drink any beverage. The tests were terminated if rectal temperature reached $39.2^{\circ} \mathrm{C}$ or $95 \%$ of $\mathrm{HR}_{\max }$ during exercise, or if any subject felt unable to continue.

\section{Analysis and statistics}

Results were expressed as the mean and standard deviation (mean $\pm \mathrm{SD}$ ) of the average of the last five minutes (at 55-60 $0^{\text {th }}$ minutes). Two-way ANOVA was used to identify any differences in mean skin temperatures by three types of clothing ensembles, two levels of climates, and two classes of activities. Post hoc test was conducted for the items showing significant differences by ANOVA. Pearson's correlation coefficient was calculated to assess the strength of association among thermal variables. Statistical significance was set at $p<0.05$. The agreement frequency (\%) with $\overline{\mathrm{T}}_{\text {sk- }}$ all (the reference value) was calculated within \pm 0.2 ${ }^{\circ} \mathrm{C}$ from the reference value: e.g., Agreement frequency $(\%)=$ number agreeing with $\left[\left(\overline{\mathrm{T}}_{\text {sk-all }}-\overline{\mathrm{T}}_{\text {sk-chest }}\right)<\right.$ $\left.\pm 0.2^{\circ} \mathrm{C}\right] \times 100$ /total number; where, total number of the subject $=8$. The reference value of $0.2^{\circ} \mathrm{C}$ was conservatively determined based on reference values from previous research [e.g., Agreements within $0.2^{\circ} \mathrm{C}$ 
(Choi et al., 1997); $0.2^{\circ} \mathrm{C}, 0.4^{\circ} \mathrm{C}, 0.6^{\circ} \mathrm{C}, 0.8^{\circ} \mathrm{C}, 1.0^{\circ} \mathrm{C}$, $1.2^{\circ} \mathrm{C}$ and $1.4^{\circ} \mathrm{C}$ (Mairiaux et al., 1987)], with the consideration of probable errors from skin temperature sensors.

\section{Results}

The time courses of $\overline{\mathrm{T}}_{\text {sk-chest, }}, \overline{\mathrm{T}}_{\text {sk-abdomen }}, \overline{\mathrm{T}}_{\text {sk-upper back, }}$, and $\overline{\mathrm{T}}_{\text {sk-all }}$ during exercise are shown in Figure 1. At the end of the $2^{\text {nd }}$ exercise at $25^{\circ} \mathrm{C}, \overline{\mathrm{T}}_{\text {sk-upper back }}$ for Control was higher compared to the initial resting value (0 to $10^{\text {th }}$ minute), while $\overline{\mathrm{T}}_{\text {sk-chest }}$ and $\overline{\mathrm{T}}_{\text {sk-abdomen }}$ were lower than the initial resting levels. For Vinyl condition, the gaps among $\overline{\mathrm{T}}_{\text {sk-chess, }}, \overline{\mathrm{T}}_{\text {sk-abdomen }}$ and $\overline{\mathrm{T}}_{\text {sk--upper back }}$ were narrower than for Control and Tyvek conditions. For Control and Tyvek conditions, $\overline{\mathrm{T}}_{\mathrm{sk}}$ began to fall immediately upon commencement of running for first few minutes, and immediate rises in $\overline{\mathrm{T}}_{\mathrm{sk}}$ were then found at the beginning of recovery. Both the immediate fall and rise were less profound for Vinyl conditions.

For rest conditions, there was no difference among $\overline{\mathrm{T}}_{\text {sk-chest }}, \overline{\mathrm{T}}_{\text {sk-abdomen }}, \overline{\mathrm{T}}_{\text {sk-upper back }}$, and $\overline{\mathrm{T}}_{\text {sk-all }}$ (Table 1). During exercise at $T_{a} 25^{\circ} \mathrm{C}, \overline{\mathrm{T}}_{\text {sk-upper back }}$ tended to be greater than both $\overline{\mathrm{T}}_{\text {sk-chest }}$ and $\overline{\mathrm{T}}_{\text {sk-abdomen, }}$, and the differences were statistically significant for Control and Tyvek conditions $(\mathrm{p}<0.05)$. In particular, $\overline{\mathrm{T}}_{\text {sk-abdomen }}$ were $0.8^{\circ} \mathrm{C}$ and $0.5^{\circ} \mathrm{C}$ lower than $\overline{\mathrm{T}}_{\text {sk-upper back }}$ for Control at both $\mathrm{T}_{\mathrm{a}} 25^{\circ} \mathrm{C}$ and $32^{\circ} \mathrm{C}$, respectively $(\mathrm{p}<$ 0.05). The difference between $\overline{\mathrm{T}}_{\text {sk-chest }}$ and $\overline{\mathrm{T}}_{\text {sk-upper back }}$ was on average $1.1^{\circ} \mathrm{C}$ for Control during exercise at $\mathrm{T}_{\mathrm{a}} 25^{\circ} \mathrm{C} \cdot \overline{\mathrm{T}}_{\text {sk-all }}$ were not statistically distinguished from $\overline{\mathrm{T}}_{\text {sk-chest }}, \overline{\mathrm{T}}_{\text {sk-abdomen }}$, and $\overline{\mathrm{T}}_{\text {sk-upper back. }} . \overline{\mathrm{T}}_{\text {sk-4pts }}$ tended to be lower than $\overline{\mathrm{T}}_{\mathrm{sk}}$ based on seven points at $25^{\circ} \mathrm{C}$, while there was no statistical difference at $32^{\circ} \mathrm{C}$ and for Vinyl conditions (Table 1).

Regarding the difference in $\overline{\mathrm{T}}_{\mathrm{sk}}$ between rest and exercise conditions, $\overline{\mathrm{T}}_{\text {sk-upper back }}$ evaluated that $\overline{\mathrm{T}}_{\text {sk }}$ during exercise was significantly greater than $\overline{\mathrm{T}}_{\mathrm{sk}}$ at rest $(\mathrm{p}<0.05)$, while $\overline{\mathrm{T}}_{\text {sk-chest }}, \overline{\mathrm{T}}_{\text {sk-abdomen, }}$, and $\overline{\mathrm{T}}_{\text {sk-all }}$ evaluated that there were no differences between rest and exercise for Control and Tyvek conditions at $25^{\circ} \mathrm{C}$ (Table 1). For Control at $32^{\circ} \mathrm{C}$, on the contrary, $\overline{\mathrm{T}}_{\text {sk-abdomen }}$ evaluated that there were no differences between rest and exercise, while $\overline{\mathrm{T}}_{\text {sk-chess, }}, \overline{\mathrm{T}}_{\text {sk-upper back }}$, and $\overline{\mathrm{T}}_{\text {sk-all }}$ evaluated that $\overline{\mathrm{T}}_{\mathrm{sk}}$ during exercise were significantly greater

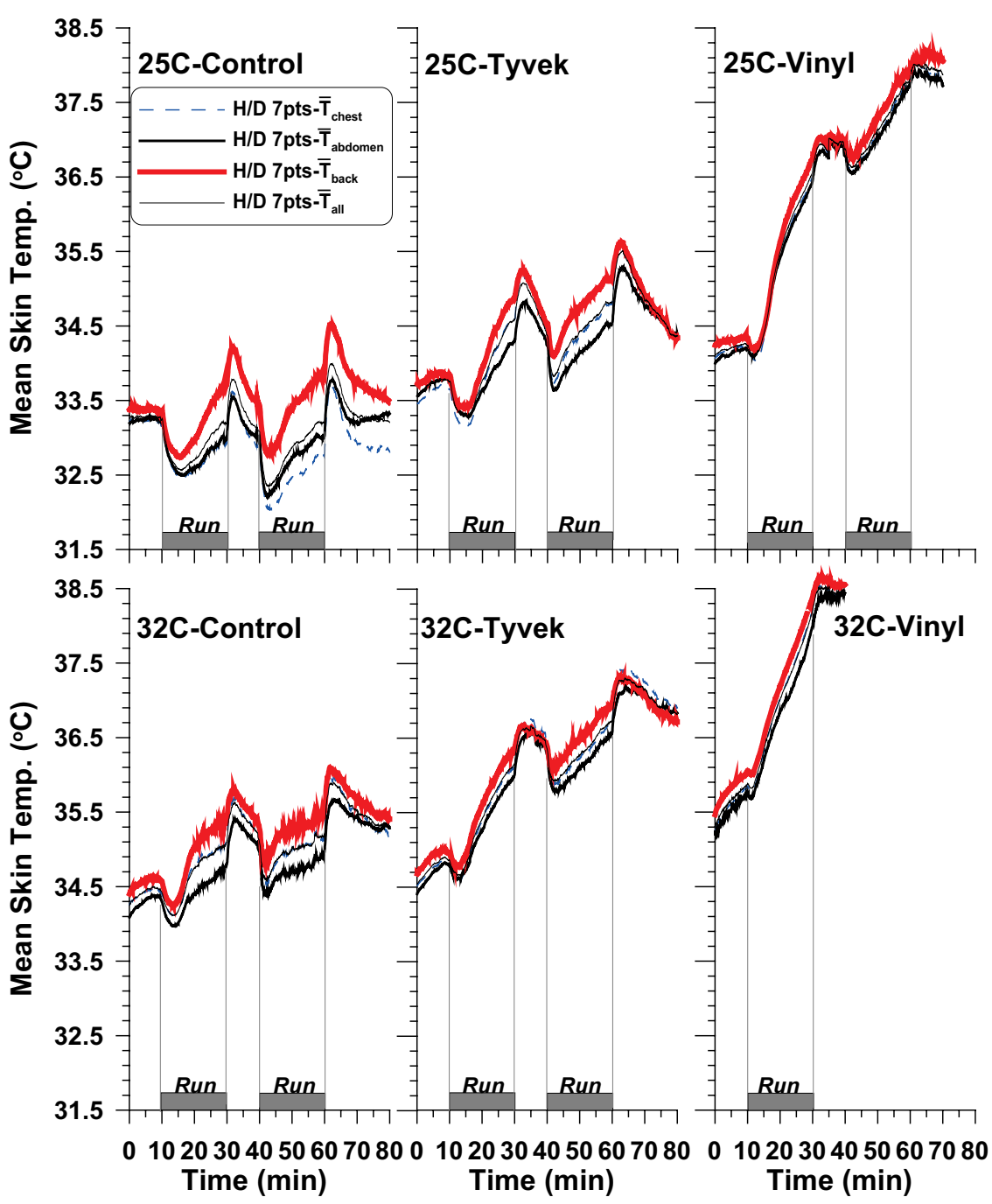

Fig. 1. Time courses of mean skin temperatures determined by Hardy and DuBois' 7-point formula during exercise. 
than $\overline{\mathrm{T}}_{\mathrm{sk}}$ at rest $(\mathrm{p}<0.05$, Table 1$)$.

Table 2 shows the results of the agreement frequency analysis. The agreements frequency (\%) to the reference values $\left(\overline{\mathrm{T}}_{\text {sk-all }}\right)$ tended to be greater at $32^{\circ} \mathrm{C}$ than at $25^{\circ} \mathrm{C}$; and in resting than in exercising conditions. In particular, the agreement frequency (\%) for
Control during exercise were lower than other cases (On average, $21 \%$ and $50 \%$ at $25^{\circ} \mathrm{C}$ and $32^{\circ} \mathrm{C}$, respectively), while the agreements frequency (\%) for Vinyl conditions at rest were greater than other cases (On average, $92 \%$ and $100 \%$ at $25^{\circ} \mathrm{C}$ and $32^{\circ} \mathrm{C}$, respectively). The agreements frequencies (\%) of $\overline{\mathrm{T}}_{\mathrm{sk}}-4 \mathrm{pts}$ to

Table 1. Mean skin temperatures according to the specified trunk sites at various environmental conditions and activities

\begin{tabular}{|c|c|c|c|c|c|c|}
\hline \multirow{2}{*}{ Rest } & \multicolumn{3}{|c|}{ 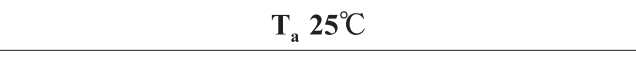 } & \multicolumn{3}{|c|}{$\mathrm{T}_{\mathrm{a}} 32^{\circ} \mathrm{C}$} \\
\hline & Control & Tyvek & Vinyl & Control & Tyvek & Vinyl \\
\hline$\overline{\mathrm{T}}_{\mathrm{sk}-4 \mathrm{pts}}$ & $32.6^{* \dagger}(0.72)$ & $33.8 \quad(0.78)$ & $34.1^{\$ \S}(0.62)$ & $34.2^{\S}(0.64)$ & $34.6^{\$ \S \S}(0.60)$ & $37.0^{\S \S}(0.55)$ \\
\hline$\overline{\mathrm{T}}_{\text {sk-chest }}$ & $33.2 \quad(0.55)$ & $34.2(0.61)$ & $34.5^{\S \S}(0.60)$ & $34.6^{8}(0.48)$ & $34.8^{\S \S \S}(0.48)$ & $36.9^{\S \S}(0.49)$ \\
\hline$\overline{\mathrm{T}}_{\text {sk-abdomen }}$ & $33.3 \quad(0.49)$ & $34.3(0.62)$ & $34.6^{\S \S}(0.65)$ & $34.8(0.09)$ & $35.0^{\S \S}(0.33)$ & $36.9^{\S \S}(0.42)$ \\
\hline$\overline{\mathrm{T}}_{\text {sk-upper back }}$ & $33.2^{\S}(0.34)$ & $34.0^{\S \S}(0.53)$ & $34.6^{\S \S}(0.45)$ & $34.6^{\S \S}(0.56)$ & $34.9^{\S \S}(0.52)$ & $36.9^{\S \S}(0.46)$ \\
\hline \multirow[t]{2}{*}{$\overline{\mathrm{T}}_{\text {sk-all }}$} & $33.2 \quad(0.43)$ & $34.2(0.56)$ & $34.6^{\S \S}(0.55)$ & $34.6^{8}(0.47)$ & $34.9^{\S \S}(0.46)$ & $36.9^{\S \S}(0.47)$ \\
\hline & \multicolumn{3}{|c|}{$\mathrm{p}<0.05$ among clothing; $\mathrm{p}<0.001$ among formulas } & \multicolumn{3}{|c|}{$\mathrm{p}<0.001$ among clothing; No difference among formulas } \\
\hline \multirow{2}{*}{ Exercise } & \multicolumn{3}{|c|}{$\mathrm{T}_{\mathrm{a}} 25^{\circ} \mathrm{C}$} & \multicolumn{3}{|c|}{$\mathrm{T}_{\mathrm{a}} 32^{\circ} \mathrm{C}$} \\
\hline & Control & Tyvek & Vinyl & Control & Tyvek & Vinyl \\
\hline$\overline{\mathrm{T}}_{\text {sk-4pts }}$ & $32.5(1.25)^{* *}$ & $34.5 \quad(0.83)$ & $37.8(0.23)$ & $35.0 \quad(0.60)$ & $36.7(0.70)$ & $38.1(0.55)$ \\
\hline$\overline{\mathrm{T}}_{\text {sk-chest }}$ & $32.7(1.03)^{*}$ & $34.7 \quad(0.51)$ & $37.6(0.28)$ & $35.1 \quad(0.44)$ & $36.6(0.69)$ & $37.9(0.56)$ \\
\hline$\overline{\mathrm{T}}_{\text {sk-abdomen }}$ & $33.0(0.75)^{*}$ & $34.5^{*}(0.59)$ & $37.6(0.23)$ & $34.9 *(0.43)$ & $36.5(0.60)$ & $37.6(0.42)$ \\
\hline$\overline{\mathrm{T}}_{\text {sk-upper back }}$ & $33.8(0.69)$ & $35.1 \quad(0.50)$ & $37.8(0.23)$ & $35.4 \quad(0.60)$ & $36.9(0.64)$ & $38.1(0.44)$ \\
\hline \multirow[t]{2}{*}{$\overline{\mathrm{T}}_{\text {sk-all }}$} & $33.2(0.81)$ & $34.8(0.49)$ & $37.7(0.22)$ & $35.1(0.40)$ & $36.6(0.62)$ & $37.9(0.43)$ \\
\hline & \multicolumn{3}{|c|}{$\mathrm{p}<0.05$ among clothing; $\mathrm{p}<0.001$ among formulas } & \multicolumn{3}{|c|}{$\mathrm{p}<0.001$ among clothing; No difference among formulas } \\
\hline
\end{tabular}

$\overline{\mathrm{T}}_{\text {sk-4pts }}$ by Ramanathan 4-point weighted mean (Ramanathan, 1964); $\overline{\mathrm{T}}_{\text {sk-chest, }}, \overline{\mathrm{T}}_{\text {sk-abdomen }}, \overline{\mathrm{T}}_{\text {sk-upper back }}$, and $\overline{\mathrm{T}}_{\text {sk-all }}$ by Hardy and DuBois 7 point weighted means (Hardy \& DuBois, 1938). The average of chest, abdomen and upper back temperatures as the single trunk temperature was used in $\overline{\mathrm{T}}_{\text {sk-all }} ;{ }^{*} \mathrm{p}<0.05$ and ${ }^{* *} \mathrm{p}<0.01$ mean significant differences to $\overline{\mathrm{T}}_{\text {sk-upper back }}$ in resting or exercise condition; ${ }^{\dagger} \mathrm{p}<0.05$ means a significant difference to $\overline{\mathrm{T}}_{\text {sk-all }}$ in resting or exercise condition; ${ }^{8} \mathrm{p}<0.05,{ }^{8 \S} \mathrm{p}<0.01$, and ${ }^{\$ \S \S} \mathrm{p}<0.001$ mean significant differences between rest and exercise conditions. All data were the average of the 55-60 minutes. There was no interaction between Clothing*Formula for resting and exercise at both $\mathrm{T}_{\mathrm{a}} 25^{\circ} \mathrm{C}$ and $32^{\circ} \mathrm{C}$.

Table 2. Agreement frequency (\%) with $\overline{\mathrm{T}}_{\text {sk-all }}$ within $\pm 0.2 \%$ from the reference values $\left(\overline{\mathrm{T}}_{\text {sk-all }}\right)$

\begin{tabular}{|c|c|c|c|c|c|c|c|}
\hline Agreement frequency $(\%)^{*}$ & & $25^{\circ} \mathrm{C}$ & & & $32^{\circ} \mathrm{C}$ & & Total \\
\hline Rest $\left(55-60^{\text {th }} \mathrm{min}.\right)$ & $\begin{array}{c}\text { Control } \\
(\mathrm{n}=8)\end{array}$ & $\begin{array}{c}\text { Tyvek } \\
(\mathrm{n}=8)\end{array}$ & $\begin{array}{l}\text { Vinyl } \\
(\mathrm{n}=8)\end{array}$ & $\begin{array}{c}\text { Control } \\
(\mathrm{n}=8)\end{array}$ & $\begin{array}{l}\text { Tyvek } \\
(\mathrm{n}=8)\end{array}$ & $\begin{array}{l}\text { Vinyl } \\
(\mathrm{n}=8)\end{array}$ & $(n=48)$ \\
\hline$\overline{\mathrm{T}}_{\text {sk-4pts, Ramanathan }}$ & 0 & 25 & 0 & 14 & 25 & 88 & 25 \\
\hline$\overline{\mathrm{T}}_{\text {sk-chest, H/D 7pts }}$ & 88 & 100 & 100 & 100 & 88 & 100 & 94 \\
\hline$\overline{\mathrm{T}}_{\text {sk-abdomen, H/D } 7 \mathrm{pts}}$ & 71 & 86 & 100 & 86 & 88 & 100 & 79 \\
\hline$\overline{\mathrm{T}}_{\text {sk-upper back, H/D 7pts }}$ & 88 & 50 & 75 & 100 & 100 & 100 & 83 \\
\hline Exercise $\left(55-60^{\text {th }}\right.$ min.) & $\begin{array}{c}\text { Control } \\
(\mathrm{n}=8)\end{array}$ & $\begin{array}{c}\text { Tyvek } \\
(\mathrm{n}=8)\end{array}$ & $\begin{array}{l}\text { Vinyl } \\
(\mathrm{n}=8)\end{array}$ & $\begin{array}{c}\text { Control } \\
(\mathrm{n}=8)\end{array}$ & $\begin{array}{l}\text { Tyvek } \\
(\mathrm{n}=8)\end{array}$ & $\begin{array}{l}\text { Vinyl } \\
(\mathrm{n}=8)\end{array}$ & $(\mathrm{n}=48)$ \\
\hline$\overline{\mathrm{T}}_{\text {sk-4pts, Ramanathan }}$ & 13 & 63 & 86 & 25 & 88 & 50 & 52 \\
\hline$\overline{\mathrm{T}}_{\text {sk-chest, H/D 7pts }}$ & 25 & 50 & 86 & 63 & 88 & 63 & 60 \\
\hline$\overline{\mathrm{T}}_{\text {sk-abdomen, } \mathrm{H} / \mathrm{D} 7 \mathrm{pts}}$ & 38 & 38 & 75 & 38 & 50 & 75 & 52 \\
\hline$\overline{\mathrm{T}}_{\text {sk-upper back, H/D } 7 \mathrm{pts}}$ & 0 & 25 & 50 & 50 & 50 & 50 & 38 \\
\hline
\end{tabular}

*Agreement frequency $(\%)=$ number agreeing with $\left[\left(\overline{\mathrm{T}}_{\text {sk-all }}-\overline{\mathrm{T}}_{\text {sk-chest, abdomen, or upper back }}\right)< \pm 0.2^{\circ} \mathrm{C}\right] \times 100 /$ total number. Agreement frequency showed significant differences by the level of activity $(p<0.05)$, and by formulas $(p<0.05)$. The significance by clothing types was $\mathrm{p}=0.077$. 
the reference values $\left(\overline{\mathrm{T}}_{\text {sk-all }}\right)$ were considerably lower for Control.

At rest, upper back temperature $\left(\mathrm{T}_{\text {upper back }}\right)$ was not statistically different from abdomen temperature $\left(\mathrm{T}_{\text {abdomen }}\right)$. During exercise, $\mathrm{T}_{\text {upper back }}$ was significantly greater than $\mathrm{T}_{\text {abdomen }}$ and the amount of difference was greater for Control than for Vinyl conditions $(\mathrm{p}<0.01$, Fig. 2-Left). During exercise, the increase $(\Delta)$ in $\mathrm{T}_{\text {upper back }}$ was greater than that in $\Delta \mathrm{T}_{\text {abdomen }}(\mathrm{p}<0.05$, Fig. 2-Right). At rest, $\mathrm{T}_{\text {abdomen }}$ tended to increase as time passed, while $T_{\text {upper back }}$ was generally maintained in the vicinity of the initial level (Fig. 2-Right).

\section{Discussion}

\section{Why is the Hardy and DuBois' 7-point formula im- portant?}

True mean skin temperature is the mean of an infinite number on the body surface. However it is known that the use of additional temperature points would not make an improvement to the reliability of the mean temperature due to the asymptotic characteristics of a composite measure (Teichner, 1958). It has been reported how many body sites are valid for the determination of weighted mean skin temperature. Teichner (1958) found that 6- and 7-point weighted mean skin temperatures are equally useful and reflect the 10-point weighted mean well. No formula including less than seven points gave a reasonably accurate mean skin temperature in a cool environment (Nielsen \& Nielsen, 1984). Choi et al. (1997) concluded that calculation of a reliable mean skin temperature must involve more than seven skin temperature measurement sites regardless of ambient temperature. It seems that the 7-point measurement is the minimum required for obtaining a valid $\overline{\mathrm{T}}_{\mathrm{sk}}$. Also it is of interest that many other sets of weighted mean formulas in current use are based on the measurements of regional body surface area by DuBois \& DuBois (1915).

As mentioned earlier, Hardy and DuBois' 7-point formula is cited with certain discrepancies in the choice of the specified site on the trunk part. It seems that the abdomen is the most frequently selected site as the trunk part in Hardy and DuBois' 7-point formula (Houdas \& Ring, 1982; Kuwabara et al., 2006; Mitchell \& Wyndham, 1969; Nielsen \& Nielsen, 1984; Parsons, 2003), followed by the chest (Lund \& Gisolfi, 1974; Teichner, 1958). Other weighted mean systems in current use stipulate the specified site as the chest rather than the abdomen (QREC's 10point, Palms \& Park's 6-point, Teichner's 6-point, Ramanathan's 4-point, and Burton's 3-point). With these discrepancies in mind, we examined the variations in mean skin temperatures when different trunk parts (the chest, abdomen, and upper back) were assigned to the single trunk temperature in Hardy and DuBois' 7-point formula.

It may be expected that mean skin temperature would gradually increase during exercise, but in practice mean skin temperature did not rise greatly for light-clad subjects exercising in a thermoneutral environment, as shown in Figure 1 (25C-Control). This may be because convective heat loss from the skin increases and the vascular skin blood flow is redistributed (e.g., initial drops). However, Table 1 shows that $\overline{\mathrm{T}}_{\text {sk-upper back }}$ for Control and Tyvek conditions during exercise at $\mathrm{T}_{\mathrm{a}} 25^{\circ} \mathrm{C}$ was significantly greater than $\overline{\mathrm{T}}_{\text {sk- }}$ upper back during rest, while $\overline{\mathrm{T}}_{\text {sk-chest }}, \overline{\mathrm{T}}_{\text {sk-abdomen }}, \overline{\mathrm{T}}_{\text {sk-all }}$ did not show any significant differences between exercise and rest. The above result could be attributed to significantly higher back temperature than abdomen temperature during exercise for lightly clothed men (Fig. 2 ). This indicates that the selection of the back to determine temperature during exercise could overestimate the true mean skin temperature.

\section{Why is upper back temperature higher than abdo- men temperature during exercise?}

The factors that influence skin temperature distribution are core temperature, blood flow, thickness of the insulating shell, thermal conductivity of the tis-
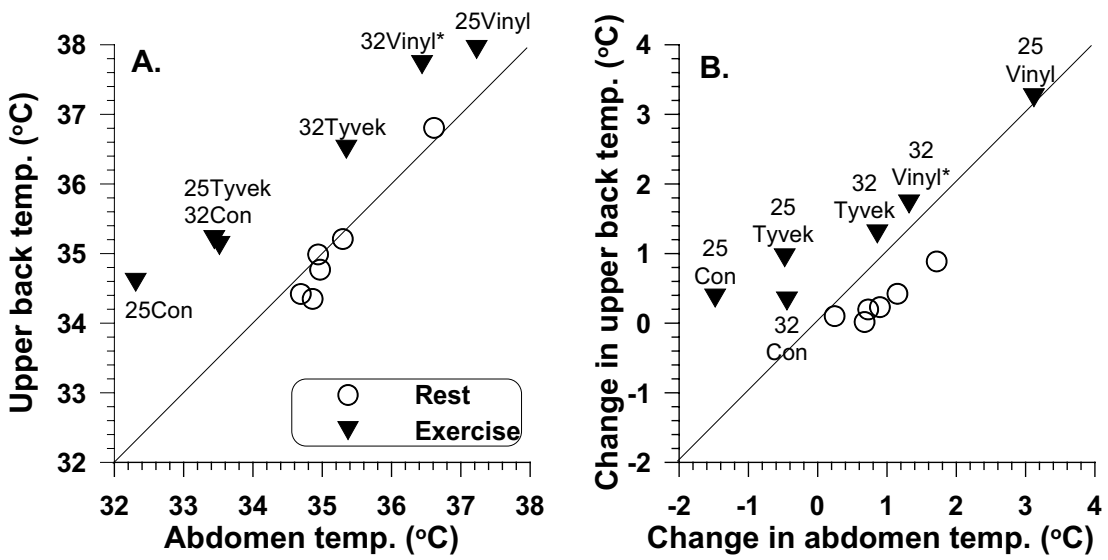

Fig. 2. Relationships between abdomen and upper back temperatures at rest and during exercise. 
sues, metabolic rate of the tissues shell, evaporative heat loss, etc. Since the chest, abdomen, and back are relatively flat body parts, the influence of heat stream according to body posture and curvatures would be negligible. Instead, the variation in skin temperatures would be attributed to the difference in thermal conductivity and/or the metabolic rate of the tissues of the chest, abdomen and upper back regions. Effective thermal conductivity is governed by physical heat conduction and skin blood flow (Ohara, 1960). Physical thermal conductivity of the tissues is associated with fat content (Ohara, 1960). It is well known that the more body fat there is at a given site, the cooler the skin is at that site (LeBlanc, 1954) and the relationship was significant at the abdomen and lower back (Frim, 1990). Subjects in the present study had a mean of $12.1 \pm 6.9 \mathrm{~mm}$ skin-fold thickness, $15.9 \pm 7.9 \mathrm{~mm}$, and $14.5 \pm 3.3 \mathrm{~mm}$ for the chest, abdomen and upper back, respectively, but there was no statistical difference. In addition, $\overline{\mathrm{T}}_{\text {sk-chest }}, \overline{\mathrm{T}}_{\text {sk-abdomen }}$, and $\overline{\mathrm{T}}_{\text {sk-upper back }}$ at rest in the $\mathrm{T}_{\mathrm{a}}$ of $25^{\circ} \mathrm{C}$ did not show any difference.

Thus, the variations between abdomen and upper back temperatures during exercise would be mostly attributed to the metabolic rate of tissues, not the difference in subcutaneous fat. During running, skin temperatures were higher over muscles than over other structures and the distribution differed dramatically from that observed before exercise (Clark et al., 1977), because heat generated in muscles underlying the skin is transferred directly by conduction and thus raises the skin temperature. Our results imply that during exercise, the muscles over the upper back are more actively mobilized than muscles in the abdomen. This can be supported by Ferretti et al. (1988). They directly measured skin-to-water heat flows of male subjects who were immersed up to their neck in water at $30^{\circ} \mathrm{C}$ using heat flow transducers. They found that local heat flows on the trunk were 14.4, 10.4, and 27.5 $\mathrm{Wm}^{-2}$ for the chest, abdomen and back sites, respectively, at rest; 68.0, 37.0, and $121.2 \mathrm{Wm}^{-2}$ during heavy exercise. The metabolic heat from the upper back was approximately twice greater than the heat from the abdomen. On the contrary, Choi et al. (1997) found that for semi-nude male subjects at rest, a percentage similarity to the infrared thermometric average of the entire trunk was greater on the abdomen and the sub-scapula than the chest and lumbar; and proposed to measure the trunk temperature on the abdomen site rather than the chest in Hardy and DuBois' 7point weighted formula. However, the results of Choi et al. (1997) should be applied to resting, not exercising persons.

\section{Influence of clothing on mean skin temperatures}

The present results demonstrated that light cloth- ing (Control) seldom interferes with heat exchange between the body and its environment during exercise, but full protective clothing - especially vapor impermeable protective clothing - considerably modified the heat exchange. The temperature variations among three sites on the trunk were greater for Control than for Vinyl conditions. This caused no significant differences among $\overline{\mathrm{T}}_{\text {sk-chest }}, \overline{\mathrm{T}}_{\text {sk-abdomen }}$, and $\overline{\mathrm{T}}_{\text {sk-upper back }}$ for Vinyl conditions. Teichner (1958) pointed out that smaller discrepancies between weighting systems occur in fully clothed men than in lightly clothed men.

\section{Which site is most representative for the trunk part in Hardy and DuBois' 7-point formula?}

In principle, a greater number of skin sites is more accurate because more closely reflects the true value of mean skin temperature. As such, we recommend the average of three trunk sites as a trunk temperature. In those cases where the attachment of many skin sensors is prohibited, a single site could be used to represent the trunk region. The ultimate purpose of the present study is to suggest the most valid single site among the chest, abdomen, and upper back during exercise. When suggesting the optimal skin site on the trunk, caution should be taken depending on the experimental condition employed. For rest conditions and/or cases where subjects wore heavy protective clothing, $\overline{\mathrm{T}}_{\text {sk-chest }}, \overline{\mathrm{T}}_{\text {sk-abdomen }}$, and $\overline{\mathrm{T}}_{\text {sk-upper back }}$ coincided with $\overline{\mathrm{T}}_{\text {sk-all }}$ with no significant difference. For lightly clothed men during exercise, $\overline{\mathrm{T}}_{\text {sk-abdomen }}$ tends to underestimate $\overline{\mathrm{T}}_{\text {sk }}$, while $\overline{\mathrm{T}}_{\text {sk-upper back }}$ tends to overestimate $\overline{\mathrm{T}}_{\mathrm{sk}}$. Most textbooks and review articles have introduced the trunk in Hardy and DuBois' 7-point formula as the abdomen (Houdas \& Ring, 1982; Kuwabara et al., 2006; Mitchell \& Wyndham, 1969; Nielsen \& Nielsen, 1984; Parsons, 2003), but the proper site selection on the trunk should be more carefully considered during exercise. For male subjects, a preferred single site on the trunk region during exercise was the chest, rather than the abdomen or the upper back. As a limitation, it needs to be mentioned that the present results are not applicable to female subjects and/or cold environments.

\section{Conclusions}

While Hardy and DuBois' 7-point weighted formula to determine $\overline{\mathrm{T}}_{\mathrm{sk}}$ has remained the authority in respect of its historical importance and contributions to human thermal environmental research, the issue on the choice of the optimum site on the trunk has been somewhat neglected. The present study showed that skin temperature distribution and dynamics over the trunk were influenced by the combined effect of air temperature, type of clothing, and activity level. Firstly, at rest in hot environments, any choice among 
the chest, abdomen, and upper back caused no significant difference in the estimation of $\overline{\mathrm{T}}_{\mathrm{sk}}$ using Hardy and DuBois' 7-point formula. Secondly, for cases where subjects wear impermeable personal protective clothing, any choice among the chest, abdomen, and upper back causes no significant difference by air temperature or activity level. Thirdly, during exercise the choice of the specified site on the trunk should be more carefully considered than at rest, because skin temperatures over the trunk were not uniform. For lightly clad men during exercise, in particular, Hardy and DuBois' 7-point weighted mean using abdomen temperature resulted in an erroneously low estimate of $\overline{\mathrm{T}}_{\mathrm{sk}}$, while Hardy and DuBois' 7-point weighted mean using upper back temperature yielded significantly greater $\overline{\mathrm{T}}_{\mathrm{sk}}$. Fourthly, the average of three sites (the chest, abdomen, and upper back) is recommended as the single trunk temperature in Hardy and DuBois' 7-point weighted formula to reduce any probable error. Reliance on the abdomen or the upper back as a site representative of the trunk is not recommended for estimating the $\overline{\mathrm{T}}_{\mathrm{sk}}$ of lightly clothed male subjects during exercise. In cases where the minimum number of skin sites is required, the chest is the preferred single site on the trunk region, during leg exercise, for male subjects.

\section{Acknowledgements}

We would like to express our thanks to Su-Young Son, Mutsuhiro Fujiwara, Shizuka Umezaki, Andrew J. Cookson and Maurice Montalvo for their technical advice and secretarial support. We are grateful to all subjects for their participation. This study was supported by a Grant-in-Aid for Scientific Research of the Japan Society for the Promotion of Science (21] 09128).

\section{References}

Burton, A.C. (1935) Human calorimetry. II.The average temperature of the tissues of the body. J Nutr 9(3): 261280.

Choi, J.K., Miki, K., Sagawa, S., Shiraki, K. (1997) Evaluation of mean skin temperature formulas by infrared thermography. Int J Biometeorol 41(2):68-75.

Clark, R.P., Mullan, B.J., Pugh, L.G.C.E. (1977) Skin temperatures during running - a study using infra-red colour thermography. J Physiol 267: 53-62.

DuBois, D., DuBois, E.F. (1915) The measurement of the surface area of man. Arch Int Med 15: 868-881.

Ferretti, G., Veicsteinas, A., Rennie, D.W. (1988) Regional heat flows of resting and exercising men immersed in cool water. J Appl Physiol 64(3): 1239-1248.

Frim, J., Livingstone, S.D., Reed, L.D., Nolan, R.W., Limmer, R.E. (1990) Body composition and skin temperature variation. J Appl Physiol 68(2):540-543.

Hardy, J.D., DuBois, E.F. (1938) The technic of measuring radiation and convection. J Nutr 15: 461-475.

Houdas, Y., Ring, E.F.J. (1982) Human body temperature: Its measurement and regulation. Plenum Press: New York.

Kaufman, W.C., Pittman, J.C. (1966) Quantitative radiometric measurement of skin temperature. J Appl Physiol 21: 302-304.

Kuwabara, K., Mochida, T., Nagano, K., Shimakura, K. (2006) Fundamental study of weighting factors for calculating mean skin temperature. Journal of the HumanEnvironmental System 9(1/2): 35-42.

LeBlanc, J. (1954) Subcutaneous fat and skin temperature. Can J Biochem Physiol 32: 354-358.

Lee, J.Y., Choi, J.W. (2009) Estimation of regional body surface area covered by clothing. Journal of the HumanEnvironment System 12(1):35-45.

Lee, J.Y., Choi, J.W., Kim, H. (2008) Determination of body surface area and formulas to estimate body surface area using the Alginate method. Journal of Physiological Anthropology. 27(2): 71-82.

Livingstone, S.D., Nolan, R.W., Frim, J., Reed, L.D., Limmer, R.E. (1987) A thermographic study of the effect of body composition and ambient temperature on the accuracy of mean skin temperature calculations. Eur J Appl Physiol Occup Physiol 56:120-125.

Livingstone, S.D., Reed, L.D., Nolan, R.W., Cattroll, S.W. (1988) Measurement of torso skin temperature under clothing. Eur J Appl Physiol 57(2):225-229.

Lund, D.L., Gisolfi, C.V. (1974) Estimation of skin temperature during exercise. J Appl Physiol 36(5): 625-628.

Mairiaux, P., Malchaire, J., Candas, V. (1987) Prediction of mean skin temperature in warm environments. Eur J Appl Physiol 56(6):686-692.

Mitchell, D., Wyndham, C.H. (1969) Comparison of weighting formulas for calculating mean skin temperature. J Appl Physiol 26(5): 616-622.

Nielsen, R., Nielsen, B. (1984) Measurement of mean skin temperature of clothed persons in cool environments. Eur J Appl Physiol 53(3):231-236.

Ohara, K. (1960) Skin temperature. In: Yoshimura et al. (eds) Essential problems in climatic physiology. Nankodo Publishing Company. pp109-143.

Parsons, K.C. (2003) Human thermal environments. CRC Press: London.

Ramanathan, N.L. (1964) A new weighting system for mean surface temperature of the human body. J Appl Physiol 19(3): 531-533.

Teichner, W.H. (1958) Assessment of mean body surface temperature. J Appl Physiol 12(2):169-176. 